\title{
Evidence for the Involvement of Interleukin 6 in Experimental Cancer Cachexia
}

Gideon Strassmann, Miranda Fong, John S. Kenney, and Chaim O. Jacob*

Department of Immunology, Otsuka America Pharmaceutical Inc., Rockville, Maryland 20850;

and *Institute of Immunology and Biological Sciences, Syntex Research, Palo Alto, California 94303

\begin{abstract}
In this report we describe an experimental model of cachexia that fulfills the criteria of an early effect with a small tumor mass not related to the growth rate of the tumor, and progressive wasting of muscle and fat without a detectable loss of appetite. C-26.IVX is a cell line derived from murine colon-26 adenocarcinoma which retains the transplantability of the original tumor and induces true cachexia in syngeneic hosts. Evidence is presented to support a role for interleukin (IL-6) as a cachectic factor in the development of cancer cachexia in this model system. Thus, increasing levels of IL-6 in C-26.IVX-bearing mice correlate with the development of cachexia. If the primary tumors were resected, mice gained weight and the levels of IL-6 in the serum were reduced significantly. Moreover, monoclonal antibody to murine IL-6 (but not anti-tumor necrosis factor antibody) was able to significantly suppress the development of key parameters of cachexia in tumor bearing mice. ( $J$. Clin. Invest. 1992. 89:1681-1684.) Key words: cancer cachexia • colon-26 tumor $\bullet$ monoclonal antibody $\bullet$ tumor necrosis factor
\end{abstract}

\section{Introduction}

Cancer cachexia, which includes depletion of muscle and fat tissue, anorexia, asthenia, hypoglycemia and anemia $(1,2)$, complicates therapeutic intervention (3) and is an important cause of death in cancer patients (4). Host-derived and tumor cell-derived tumor necrosis factor (TNF) ${ }^{1}$ has been suggested as a mediator of the metabolic changes associated with cachexia because it can suppress key metabolic enzymes and can induce cachexia in experimental animals (5-7). However, extrapolation of these findings to clinical cancer has been difficult and yields mixed results $(8-10)$. Thus the precise mechanism of cancer cachexia remains largely unknown $(4,11)$.

Only few animal transplantable tumors are capable of inducing cachexia in vivo (12). Even fewer of the experimental models that have been used to study the mechanism of cachexia fulfill the criteria that cachexia should be an early effect of the tumor and be present with a small tumor burden $(4,12)$. Instead, cachexia is usually studied in rapidly growing rodent

Address reprint requests to Dr. Strassmann, Department of Immunology, Otsuka America Pharmaceutical Inc., 9900 Medical Center Drive, Rockville, MD 20850.

Received for publication 11 November 1991 and in revised form 7 January 1992.

1. Abbreviations used in this paper: SAP, serum amyloid P; TNF, tumor necrosis factor.

J. Clin. Invest.

(c) The American Society for Clinical Investigation, Inc.

$0021-9738 / 92 / 05 / 1681 / 04 \$ 2.00$

Volume 89, May 1992, 1681-1684 tumors which appear as a late effect usually just before death when the tumor mass has grown to a large size. These models attribute the cachexia to a decrease in food intake and competition of the tumor with the host for essential nutrients. Such tumor models are thus not indicative of the conditions of cancer patients with cachexia $(4,12)$.

Murine colon-26 adenocarcinoma is an undifferentiated tumor induced by a carcinogen ( $N$-nitroso- $N$-methylurethan) and has been shown to induce cachexia in mice $(12,13)$. Here we describe a cell line that was derived from this tumor and show that it induces true cachexia. Moreover, evidence is presented to suggest that interleukin 6(IL-6) is involved in development of cancer cachexia in this model.

\section{Methods}

Mice. Male Balb/c $\times$ DBA/2 (CD) F1 mice purchased from Charles River Breeding Laboratories (Wilmington, MA) were used at 10-12 wk of age.

Generation of C-26.IVX line. The chemically induced, colon-26 (C-26) undifferentiated carcinoma was obtained from the Tumor Repository of the National Cancer Institute (Frederick, MD). The tumor was minced into small fragments and transferred s.c. to the right flank of CDF1 mice. $10 \mathrm{~d}$ later, the tumor was excised and minced, and a single cell suspension was prepared by treatment with collagenase $(250$ $\mu \mathrm{g} / \mathrm{ml})$ and DNAse $(1 \mu \mathrm{g} / \mathrm{ml})$ purchased from Sigma Chemical Co. (St. Louis, MO) for $30 \mathrm{~min}$ at room temperature. After washing the cells, 1 $\times 10^{6}$ cells $/ \mathrm{ml}$ were incubated for $24 \mathrm{~h}$ at $37^{\circ} \mathrm{C}$ in RPMI 1640 supplemented with 10\% FCS (Complete medium, Hyclone Laboratories, Inc., Logan, UT). The flask was tapped against a hard surface, and nonadherent cells were collected. This procedure was repeated several times and the resulting cells were expanded and frozen. Subculture of this line termed C-26.IVX did not require trypsinization because the cells were loosely adherent. Transfer of these cells between passages 3 and $12\left(0.5 \times 10^{6}\right.$ per mouse) reproducibly caused tumors and cancer cachexia.

Cytokine assays. IL-6 was determined using IL-6-dependent B-9 cells as described (14). $1 \mathrm{U}$ of IL-6 was defined as the amount required for half-maximal stimulation of cell proliferation in the assay. Addition of anti-IL-6 monoclonal antibody completely abolished cell proliferation in this assay (data not shown). Total TNF was determined in the L929 bioassay as described (14) and an ELISA as described (15). The lowest detectable level of murine TNF- $\alpha$ was $30 \mathrm{pg} / \mathrm{ml}$ in the bioassay and $15 \mathrm{pg} / \mathrm{ml}$ in the ELISA.

Total IL-1 was determined by a radioreceptor assay as described (14), using endotoxin-induced macrophage-conditioned medium and human recombinant IL-1 $\beta$ (gift from Dr. Y. Hirai, Otsuka, Japan) as positive controls. The lowest detectable level of IL-1 in this assay was $200 \mathrm{pg} / \mathrm{ml}$.

Antibodies. Hybridoma MP5-20F3 producing rat $\mathrm{IgG}_{1}$ anti-mouse IL-6 antibody was a gift from Dr. John Abrams (DNAX Inc., Palo Alto, CA). For in vivo studies, pharmaceutical grade antibody was produced by in vitro cell culture in a perfusion system (Cell Pharm Bioreactor, Unisyn Fibertec Corp., San Diego, CA). The antibody was purified to $>98 \%$ on Prosep Protein A (Porton Products, Maidenhead, UK). Monoclonal TN3.19.12 is a hamster anti-murine TNF antibody and 

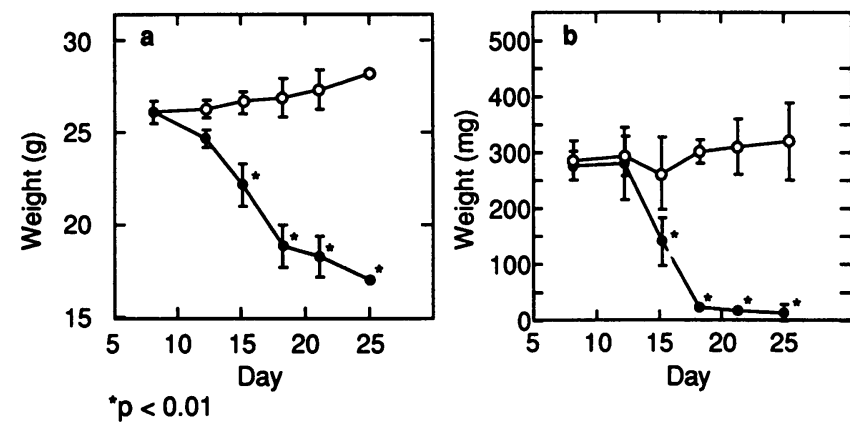

was a gift from Dr. Robert Schreiber (Washington University, St. Louis, MO). TN3.19.12 antibody was purified from culture supernatant by using protein A-agarose as described (15). Isotype control rat IgG was obtained from Sigma Chemical Co.

Measurements of cachexia markers. Carcass weight was quantified after bleeding by retroorbital plexus puncture $(0.5 \mathrm{ml}$ per mouse) and the removal of the tumor. Serum was obtained by clotting of blood at room temperature for $1 \mathrm{~h}$. Dry weight (a marker for total muscle tissue) was determined after $3 \mathrm{~d}$ of oven drying $\left(85^{\circ} \mathrm{C}\right)$ of the carcass. Measurements of serum glucose were performed using an Ektachem DT-60 analyzer (Eastman Kodak Co., Rochester, NY). Serum amyloid $P$ (SAP) was determined by rocket immunoelectrophoresis as described (16) using rabbit anti-mouse SAP antiserum and SAP standards (Calbiochem Behring Corp., San Diego, CA).

Statistical analysis. Differences in weight of tumor, body, carcass, epididymal fat, gastrocnemius muscle, heart, and liver and glucose and SAP levels were compared by using computerized analysis of variance (ANOVA). Results throughout the article are expressed as mean \pm SD.

\section{Results and Discussion}

From colon-26 tumor, cell line C-26.IVX was derived by repeated removal of contaminating host adherent cells as described in Methods. This new line grows well in tissue culture, retains the transplantability of the original tumor, and induces cachexia in syngeneic hosts. As shown in Fig. 1 this tumor line is capable of inducing true cachexia, as significant carcass weight has been lost in the early stages of tumor growth. Tumor-bearing mice started losing weight ca. day 12 when tumor weight was only $\sim 0.7 \mathrm{~g}(\sim 3 \%$ of total body weight $)$ and continued to lose weight until ca. day 21 when their weight was $\sim 10 \mathrm{~g}$ less than age- and sex-matched controls. The loss of carcass weight during tumor growth was essentially the wasting of muscle and adipose tissue. Significant wasting of epididymal adipose tissue was observed $\sim 15 \mathrm{~d}$ after tumor inoculation and was almost entirely depleted by day 18 (Fig. 1). Several physiological changes associated with cachexia were also monitored. Hypoglycemia started ca. day 12, when body wasting was still slight, and glucose levels fell to less than half of their control levels by day 18 whereas the concentration of acutephase proteins in the blood, such as SAP, were significantly elevated (Table I). A significant decrease in the weights of heart and liver tissue as well as gastrocnemius muscle was observed in C-26-bearing mice (Table I). It is unlikely that the rapid wasting of body tissue in the mice bearing C-26.IVX cells was due to anorexia, because food intake was not reduced while they were losing weight. Thus, between days 11 to 18 postinoc-

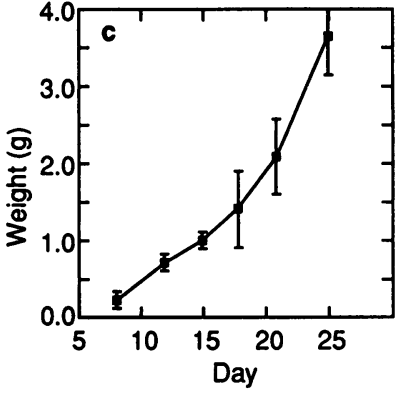

Figure 1. Quantification of cachectic markers produced by C-26.IVX line when transplanted in vivo. 3-mo-old $(\mathrm{Balb} / \mathrm{c} \times \mathrm{DBA} / 2) \mathrm{F} 1$ male mice were injected with C-26.IVX cells $\left(0.5 \times 10^{6}\right.$ cells per mouse, s.c. in the right flank). The cells were maintained in culture and no trypsinization was required because these cells are loosely adherent. At the indicated time points, animals were killed, the tumor was excised, and weights of the carcasses $(a)$, epididymal fat $(b)$, and tumor mass $(c)$ were recorded. Each time point represent the mean $\pm S D$ of four to five tumor-bearing (๑) or age-matched control mice (0). ${ }^{*} P$ values $<0.01$.

ulation, the cumulative food intake of the C-26.IVX-bearing mice ( $49 \mathrm{~g}$ ) was similar to that of the non-tumor-bearing controls $(50 \mathrm{~g})$. Diarrhea or other evidence of malabsorption were not observed in C-26-bearing mice. In addition, piloerection and asthenia were observed only in mice bearing C-26.IVX. Taken together these observations suggest that the C-26.IVXbearing mouse is an appropriate model for cancer cachexia.

Next, we tested the production of possible mediators of cachexia in this model. To our surprise, TNF- $\alpha$ and IL-1 could not be detected in either the conditioned medium of colon- 26 tumor or in the C-26.IVX line. Furthermore, TNF- $\alpha$ was not detectable in the serum of mice bearing the tumor while they were developing progressive cachexia. On the other hand, high levels of IL-6 could be identified in colon-26 tumor-conditioned medium as well as in the serum of C-26.IVX-bearing mice (Table II). IL-6 was detected in C-26.IVX tissue culture supernatant, although at a level $\sim 60$-fold lower than in the tumor. In further experiments we found that the tumor is contaminated with up to $6 \%$ of host-derived macrophages. The interaction between tumor cells and host macrophages is responsible for the elevated IL-6 produced by the tumor (data not shown).

When the C-26.IVX line was transplanted into mice, a correlation between the magnitude of weight loss and the appearance of IL- 6 in the circulation was found (Table II). To test the possibility of IL-6 as a cachectic factor we attempted to inhibit the action of IL-6 with neutralizing anti-murine IL-6

Table I. Summary of the Cachexia Markers Obtained from an Experiment 18 d after Tumor Inoculation

\begin{tabular}{lcc}
\hline & \multicolumn{2}{c}{ Group } \\
\cline { 2 - 3 } \multicolumn{1}{c}{ Parameter } & $\begin{array}{c}\text { Control } \\
(n=8)\end{array}$ & $\begin{array}{c}\text { C.26.IVX } \\
(n=8)\end{array}$ \\
\hline Carcass wt $(g)$ & $23.3 \pm 1.4$ & $16.9 \pm 0.9^{*}$ \\
Tumor wt $(g)$ & - & $1.3 \pm 0.2$ \\
Epididymal fat $(m g)$ & $370 \pm 15$ & $25 \pm 10^{*}$ \\
Dry wt $(g)$ & $8.6 \pm 0.8$ & $5.3 \pm 0.4^{*}$ \\
Glucose $(m g / d l)$ & $140 \pm 15$ & $70 \pm 18^{*}$ \\
SAP $(\mu g / m l)$ & $20 \pm 3$ & $871 \pm 25^{*}$ \\
Gastrocnemius $(m g)$ & $185 \pm 10$ & $85 \pm 21^{*}$ \\
Heart wt $(m g)$ & $115 \pm 6$ & $94 \pm 4^{*}$ \\
Liver wt $(g)$ & $1.07 \pm 006$ & $0.88 \pm 0.05^{*}$ \\
\hline
\end{tabular}

There were eight mice per group in this experiment. ${ }^{*} P$ values $<0.01$. 
Table II. Cytokine Profile of Colon-26 Tumor

\begin{tabular}{lcccccccc}
\hline & & & \multicolumn{5}{c}{ C-26.IVX-bearing mice } \\
\cline { 5 - 7 } Cytokine & $\begin{array}{c}\text { C-26. } \\
\text { tumor }\end{array}$ & $\begin{array}{c}\text { C-26.IVX } \\
\text { line }\end{array}$ & 9 & 12 & 15 & 18 & $\begin{array}{c}\text { Control } \\
\text { mice }\end{array}$ \\
\hline & & \multicolumn{6}{c}{$U / m l$} \\
IL-6 & $1900 \pm 100^{*}$ & $40 \pm 15$ & $10 \pm 5$ & $75 \pm 10$ & $270 \pm 17$ & $570 \pm 40$ & $10 \pm 5$ \\
TNF & ND & ND & ND & ND & ND & ND & ND \\
IL-1 & ND & ND & NT & NT & NT & NT & NT \\
& & & & & & & \\
\hline
\end{tabular}

Conditioned medium was obtained by incubation of single-cell suspension of C- 26 tumor $\left(5 \times 10^{7}\right.$ cells $)$ derived by enzymatic degradation with collagenase $(250 \mu \mathrm{g} / \mathrm{ml})$ and DNAse $(1 \mu \mathrm{g} / \mathrm{ml})$ or by culturing C-26.IVX cell line ( $5 \times 10^{7}$ cells) in RPMI-1640 for $24 \mathrm{~h}$. The medium was centrifuged and concentrated $\sim 20$-fold and cytokine levels were determined as described in Methods. Results of three separate experiments are shown. Abbreviations: ND, not detected (below sensitivity level); NT, not tested. ${ }^{*}$ Data is given $\pm \mathrm{SD}$.

monoclonal antibody, and were able to demonstrate that inhibition of IL-6 activity abolished the C-26.IVX induced cachexia.

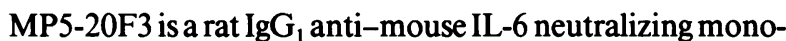
clonal antibody which is a potent and specific antagonist of mouse IL-6 bioactivity (17). Anti-IL-6 pretreatment of mice subsequently challenged with lethal doses of Escherichia coli infection protects mice from death (17). Monoclonal TN3.19.12 is a hamster anti-murine TNF antibody that reacts with both TNF- $\alpha$ and TNF- $\beta$ and has been shown to neutralize TNF activities in vivo $(15,18)$, and at the amounts used here the antibody completely blocked LPS-induced hypertrygliceridemia (not shown).

Age-matched mice were randomized to receive an injection of $0.5 \times 10^{6} \mathrm{C}$-26.IVX cells. On days 6 and 12 after tumor inoculation, mice received either PBS or monoclonal antibody against murine IL-6 $(1 \mathrm{mg} / \mathrm{mouse}$ per injection $)$ or monoclonal anti-murine TNF neutralizing antibody $(0.5 \mathrm{mg} / \mathrm{mouse}$ per injection). Animals were killed on day 16. As shown in Table III, experiment 1 , anti-IL-6 but not anti-TNF antibody was able to significantly suppress the development of cachexia as is evident from comparison of body compositional analysis. Whereas carcass weight and epididymal fat was significantly increased by anti-IL- 6 treatment, tumor weight was not changed, indicating that this treatment affected the host directly. Daily measurements of total weight (from day 12 to day 16), did not reveal any difference between C-26-bearing mice treated with anti-IL-6 monoclonal antibody and age-matched controls (data not shown).

Moreover, in a separate experiment also depicted in Table III, the reversal of various metabolic parameters of cachexia by anti-IL-6 antibodies parallel the reduction in the level of IL-6 in the serum of treated mice. No such effect could be seen in tumor-bearing mice treated with a nonrelevant rat IgG antibody. In addition, after the primary tumor was resected on day 15 , the mice gained weight, piloerection and asthenia disappeared, and IL- 6 levels in the serum were reduced significantly within $5 \mathrm{~d}$ (Table IV). In conclusion, three lines of evidence support the role of IL- 6 as an important cachectic factor in the development of cancer cachexia: $(a)$ measurable circulatory levels of IL- 6 can be identified in colon-26-bearing mice; $(b)$ the serum level of IL- 6 correlates with the degree of cachexia;

Table III. Reversal of C-26.IVX-induced Cachexia by Anti-IL-6 but Not by Anti-TNF Antibody

\begin{tabular}{|c|c|c|c|c|c|}
\hline Parameter & Group $1(n=5)$ & Group $2(n=6)$ & Group $3(n=6)$ & $P$ value & Group $4(n=6)$ \\
\hline \multicolumn{6}{|l|}{ Experiment 1} \\
\hline Tumor inoculation & C-26.IVX & C-26.IVX & C-26.IVX & - & - \\
\hline Injection & PBS & anti-TNF & anti-IL-6 & - & PBS \\
\hline Total wt $(g)$ & $19.6 \pm 0.4$ & $20.3 \pm 0.4$ & $23.2 \pm 0.9$ & 0.0005 & $25.9 \pm 0.7$ \\
\hline Carcass wt $(g)$ & $16.7 \pm 0.4$ & $16.8 \pm 0.3$ & $19.7 \pm 0.6$ & 0.0004 & $23.3 \pm 0.6$ \\
\hline Tumor wt $(g)$ & $0.92 \pm 0.1$ & $1.07 \pm 0.2$ & $0.88 \pm 0.13$ & N.S. & - \\
\hline Dry wt $(g)$ & $5.6 \pm 0.2$ & $5.6 \pm 0.5$ & $6.8 \pm 0.3$ & 0.006 & $8.9 \pm 0.3$ \\
\hline Epididymal fat $(m g)$ & $49 \pm 9$ & $54 \pm 28$ & $142 \pm 35$ & 0.002 & $292 \pm 67$ \\
\hline \multicolumn{6}{|l|}{ Experiment 2} \\
\hline Tumor inoculation & C-26.IVX & C-26.IVX & C-26.IVX & - & - \\
\hline Injection & PBS & rat IgG & anti-IL-6 & - & PBS \\
\hline Total wt $(g)$ & $21.6 \pm 1.6$ & $22.1 \pm 1.9$ & $26.0 \pm 1.7$ & 0.004 & $27.3 \pm 1.2$ \\
\hline Carcass wt $(g)$ & $19.3 \pm 1.5$ & $19.8 \pm 1.8$ & $23.9 \pm 1.6$ & 0.002 & $25.7 \pm 1.1$ \\
\hline Tumor wt $(g)$ & $1.3 \pm 0.1$ & $1.4 \pm 0.2$ & $1.2 \pm 0.1$ & N.S. & - \\
\hline Dry wt $(g)$ & $5.9 \pm 0.4$ & $6.3 \pm 0.5$ & $9.2 \pm 0.6$ & 0.003 & $10.3 \pm 0.3$ \\
\hline Epididymal fat $(m g)$ & $55 \pm 15$ & $62 \pm 35$ & $190 \pm 75$ & 0.003 & $301 \pm 58$ \\
\hline Serum glucose $(m g / d l)$ & $39 \pm 14$ & $43 \pm 19$ & $82 \pm 9$ & 0.0005 & $131 \pm 6$ \\
\hline Serum IL-6 $(U / m l)$ & $233 \pm 47$ & $256 \pm 28$ & $76 \pm 9$ & 0.0001 & $15 \pm 3$ \\
\hline SAP $(\mu g / m l)$ & $1080 \pm 50$ & $1200 \pm 110$ & $310 \pm 20$ & 0.0003 & $20 \pm 3$ \\
\hline
\end{tabular}

Tumor-bearing mice were randomized to receive intraperitoneally PBS or MP5-20F3 ( $1 \mathrm{mg} / 0.5 \mathrm{ml}$ per mouse), or TN3.19.12 (0.5 mg/0.5 ml per mouse), or purified rat IgG $(1 \mathrm{mg} / 0.5 \mathrm{ml}$ per mouse), respectively. In experiment 1 treatment was given on days 6 and 12 post-C-26.IVX cell inoculation (as described in Fig. 1), and animals were killed on day 16, whereas in experiment 2 the various treatments were administered on days 7 and 13 after inoculation of C-26.IVX cells, and animals were killed on day 17. Cachectic markers were quantified as described in Methods. $P$ values for statistical significance of the results obtained in group 3 vs. groups 1 and 2 are given. No statistical difference of total weight, carcass weight, and dry weight between groups 3 and 4 in experiment 2 could be observed. 


\begin{tabular}{|c|c|c|c|c|c|c|}
\hline Group & $\begin{array}{l}\text { Host wt at } \\
\text { operation }\end{array}$ & Tumor wt & $\begin{array}{l}\text { IL-6 in serum at } \\
\text { operation }\end{array}$ & $\begin{array}{c}\text { Host wt } 3 \mathrm{~d} \\
\text { post-resection }\end{array}$ & $\begin{array}{c}\text { Host wt } 5 \mathrm{~d} \\
\text { post-resection }\end{array}$ & $\begin{array}{c}\text { IL-6 in serum } 5 \mathrm{~d} \\
\text { post-resection }\end{array}$ \\
\hline & $g$ & $g$ & $U / m l$ & $g$ & $g$ & $U / m l$ \\
\hline Tumor-bearing $(n=7)$ & $20.7 \pm 0.7$ & $1.2 \pm 0.12$ & $190 \pm 20$ & $24.9 \pm 0.7^{\ddagger}$ & $25.9 \pm 0.6^{\ddagger}$ & $44 \pm 7$ \\
\hline Control $(n=7)$ & $26.3 \pm 1.3^{*}$ & - & $10 \pm 3$ & $26.6 \pm 1.2$ & $26.9 \pm 1.1$ & $12 \pm 3$ \\
\hline
\end{tabular}

Mice were inoculated with C-26.IVX cells as described in the legend to Fig. 1. On day 15 mice were anesthetized and the entire tumor mass was resected. Age-matched control mice received a sham operation. Weight of animals was monitored daily. Serum IL-6 levels were determined as described in Methods. ${ }^{*} P=0.005$. ${ }^{\ddagger} \mathrm{NS}$.

(c) inhibition of the action of IL-6 abolishes key parameters of cachexia including muscle and fat wasting, hypoglycemia, and hepatic acute-phase response.

The integral role of IL-6 in stimulating hepatic acute-phase response (19), which is frequently seen in cancer patients (20), the fact that elevated levels of IL- 6 circulate in the serum of tumor-bearing mice (21), and the recent report on the decrease in body weight of nude mice given IL-6-transfected Chinese hamster ovary cells (22) corroborate the data presented here in supporting a major role for IL-6 in clinical cancer cachexia. In addition, alterations in lipid metabolism resulting in depletion of host body fat is believed to involve the suppression of the enzyme lipoprotein lipase and appears to be a hallmark of clinical cancer cachexia (2). Several cytokines including TNF, IL1 , and IL-6 have been implicated as participants in cachexia because they mediate hepatic lipogenesis and inhibit lipoprotein lipase activity $(2,23,24)$. TNF does not appear to play a central role in C-26-induced cachexia. However, TNF has been shown to participate in weight loss associated with anorexia (25). Because C-26-bearing mice are not anorectic, the fact that TNF seems not to be involved is not surprising. Recently, treatment of tumor-bearing rats with antibody against IFN- $\gamma$ but not with antibody against TNF was shown to partially reverse some cachectic changes associated with cancer (26). Because IL-1, TNF, and IFN- $\gamma$ are known to stimulate or to serve as a cosignal for IL-6 production $(19,27)$ and because IL-6 also mediates some of the actions of TNF and IL-1 in vivo (21), it is possible that IL-6 is a common mediator involved in cachectic events in many, if not all, experimental cachexia models. Whether IL-6 is a mediator common to all clinical cancer cachexia or just to certain types of cancer remains to be established. Furthermore, our work suggests that specific strategies to attempt to remove or neutralize IL-6 activity in cancer patients will likely improve antitumor treatment.

\section{References}

1. Norton, J. A., J. L. Peacock, and S. D. Morrison. 1987. Cancer cachexia. CRC Crit. Rev. Oncol. Hematol. 7:289.

2. Langstein, H. N., and J. A. Norton. 1991. Mechanisms of cancer cachexia. Hematol. Oncol. Clin. North Am. 5:103-123.

3. Van Eys, J. 1982. Effect of nutritional status on response to therapy. Cancer Res. 42(Suppl.): 747-753.

4. Tisdale, M. J. 1991. Cancer cachexia. Br. J. Cancer. 63:337-342.

5. Oliff, A., D. Defeo-Jones, and M. Boyer, 1987. Tumors secreting human TNF/cachectin induce cachexia in mice. Cell. 50:555-563.

6. Tracey, K. J., H. Wei, K. R. Manogue, Y. Fong, B. Beutler, R. S. Cotran, A Cerami, and S. F. Lowry. 1988. Cachecin/tumor necrosis factor induces cachexia, anemia, and inflammation. J. Exp. Med. 167:1211-1227.

7. Sherry, B. A., J. Gelin, Y. Fong, M. Mariano, H. Wei, A. Cerami, S. F. Lowry, K. G. Lundholm, and L. L. Moldawer. 1989. Anticachectin/tumor necrosis factor antibodies attenuate development of cachexia in tumor models. FASEB (Fed. Am. Soc. Exp. Biol.) J. 3:1956-1962.
8. Waage, A., T. Espevik, and J. Lamvik. 1987. Detection of TNF-like cytotoxicity in serum from patients with septicemia but not from untreated cancer patients. Scand. J. Immunol. 24:739-744.

9. Socher, S. H., D. Martinez, J. B. Craig, J. G. Kuhn, and A. Oliff. 1988. Tumor necrosis factor not detectable in patients with clinical cancer cachexia. $J$. Natl. Cancer Inst. 80:595-598.

10. Balkwill, F., R. Osborne, F. Burke, S. Naylor, D. Talbot, and W. Fiers. 1987. Evidence for tumor necrosis factor/cachectin production in cancer. Lancet. 2:1229-1231.

11. Oliff, A. 1988. The role of tumor necrosis factor (cachectin) in cachexia. Cell. $54: 141-142$.

12. Tanaka, Y., H. Eda, T. Tanaka, T. Udagawa, T. Ishikawa, and T. Taguchi. 1990. Experimental cancer cachexia induced by transplantable colon 26 adenocarcinoma in mice. Cancer Res. 50:2290-2295.

13. Corbett, T. H., D. P. Griswold, B. J. Roberts, J. C. Peckham, and F. M. Schabel. 1975. Tumor induction relationships in development of transplantable cancers of the colon in mice for chemotherapy assays, with a note on carcinogen structure. Cancer Res. 35:2434-2439.

14. Strassmann, G., D. R. Bertolini, S. B. Kerby, and M. Fong. 1991. Regulation of murine mononuclear phagocyte inflammatory products by macrophage colony-stimulating factor. J. Immunol. 147:1279-1285.

15. Sheehan, K. C. F., N. H. Ruddle, and R. D. Schreiber. 1989. Generation and characterization of hamster monoclonal antibodies that neutralize murine tumor necrosis factor. J. Immunol. 142:3884-3890.

16. Laurell, C.-B. 1966. Quantitative estimation of proteins by electrophoresis in agarose gel containing antibodies. Anal. Biochem. 15:45-52.

17. Fletcher Starnes, H., M. K. Pearce, A. Tewari, J. H. Yim, J.-C. Zou, and J. S. Abrams. 1990. Anti-IL-6 monoclonal antibodies protect against lethal Escherichia coli infection and lethal tumor necrosis factor- $\alpha$ challenge in mice. J. Immunol. 145:4185-4191.

18. Ruddle, N. H., C. M. Bergman, K. M. McGrath, E. G. Lingenheld, M. L. Grunnet, S. J. Padula, and R. B. Clark. 1990. An antibody to lymphotoxin and tumor necrosis factor prevents transfer of experimental allergic encephalomyelitis. J. Exp. Med. 172:1193-1198.

19. J. Van Snick. 1990. Interleukin-6: an overview. Annu. Rev. Immunol. 8:253-278.

20. Moldawer, L. L., M. Georgieff, and K. G. Lundholm. 1987. Interleukin 1, tumor necrosis factor and the pathogenesis of cancer cachexia. Clin. Physiol. 7:263-274.

21. McIntosh, J. K., D. M. Jablons, J. J. Mule, R. P. Nordan, S. Rudikoff, M. T. Lotze, and S. A. Rosenberg. 1989. In vivo induction of IL-6 by administration of exogenous cytokines and detection of de novo serum levels of IL-6 in tumor-bearing mice. J. Immunol. 143:162-167.

22. Black, K., I. R. Garrett, and G. R. Mundy. 1991. Chinese hamster ovary cells transfected with the murine IL-6 gene cause hypercalcemia as well as cachexia, leukocytosis and thrombocytosis in tumor bearing nude mice. Endocrinology. 128:2657-2659.

23. Beutler, B., J. Mahoney, N. I. Trang, P. Pekala, and A. Cerami. 1985. Purification of cachectin, a lipoprotein lipase suppressing hormone secreted by endotoxin induced RAW 264.7 cells. J. Exp. Med. 161:984-995.

24. Grunfeld, C., M. Soved, S. Adi, A. H. Moser, W. Fries, C. A. Dinarello, and K. R. Feingold. 1991. Interleukin-4 inhibits stimulation of hepatic lipogenesis by tumor necrosis factor, interleukin- 1 and interleukin- 6 but not by interferon- $\alpha$. Cancer Res. 51:2803-2807.

25. Michie, H. R., M. L. Sherman, D. R. Spriggs, J. Rounds, M. Christie, and D. W. Wilmore. 1989. Chronic TNF infusion causes anorexia but not accelerated nitrogen loss. Ann. Surg. 209:19-24.

26. Langstein, H. N., G. M. Doherty, D. L. Fraker, C. M. Buresh, and J. A. Norton. 1991. The roles of $\gamma$-interferon and tumor necrosis factor $\alpha$ in an experimental rat model of cancer cachexia. Cancer Res. 51:2302-2306.

27. Sanceau, J., F. Beranger, C. Gaudelet, and J. Wietzerbin. 1989. IFN- $\gamma$ is an essential cosignal for triggering IFN $\beta 2 / B S F-2$ gene expression in human monocytic cell lines. Ann. NY Acad. Sci. 557:130-143. 